\title{
Evaluation of the Effect of Drying and Rewetting Cycles in Eucalyptus Pulps
}

\author{
Julian E. Mejia B., Juliano Fiorelli, Holmer Savastano Jr., and Lisa Vidil
}

\begin{abstract}
In the fibrocement industry of tiles and sheets, various kinds of natural fibers are used as reinforcement to improve the properties of the products. Although the use of fibrocement material presents a great potential due to the low cost and the high availability of vegetable fibers, several investigations have showed a behavior of low durability and rapid deterioration of the cellulosic material in an alkaline medium. With the purpose of contributing to this knowledge, the present study evaluated bleached and unbleached cellulosic pulp of eucalyptus before and after the thermal treatment consisting of 4 cycles of drying and rewetting denominated hornification. Analysis by scanning electron microscopy (SEM) and X-ray diffraction (XRD) were performed. SEM images indicated morphological changes on the surface of treated bleached and unbleached eucalyptus cellulosic pulps. Based on XRDresults, the treatment hornification did not cause the deterioration of crystalline cellulose of the fibers.
\end{abstract}

Index Terms-Cement-based matrix, cellulosic fiber, hornification, composite.

\section{INTRODUCTION}

In many countries the use of asbestos chrysolite as a reinforcement of cement based inorganic matrices has been banned for the last years. A significant effort is being conducted to develop a product that meets market needs. Vegetable fibers are an alternative to this problem due to their high availability, reduced cost, lower energy consumption (required for their extraction and production when compared to manufactured fibers) and their biodegradable behavior making them environmentally friendly[1]-[3]. However, despite these advantages, the use of such material in cement matrices presents some drawbacks that have been noticed by several scientific researches: these issues are based onthe low durability of natural fibers in alkaline medium and their low adhesion to the cementitious matrix [3], [4].

As an alternative to improve the performance of vegetable fibers in an alkaline environment, physical and/or chemical treatments areperformed on cellulosic fibers. They aim to alterfiber surface and make this material more stable within the cement matrix [5], [6]. One of these procedures involves subjecting the fibers to several cycles of drying and

Manuscript submitted April 4, 2014; revised July 1, 2014. This work was supported by the University of São Paulo and private company Suzano Papel $\&$ Celulose.

Julian Eduardo Mejia Ballesteros, Juliano Fiorelli, and Holmer Savastano Junior are with Animal Science, University of São Paulo, Pirassununga-SP, CEP, 13635-900, Brasil (e-mail: Julian.mejia@usp.br, julianofiorelli@usp.br, holmersj@usp.br).

Lisa Vidil is with the Laboratory COVACHIM-M2A3592, UFR SEN, University of the French West Indies and French Guiana, BP 230, 97157 Pointe-à-Pitre Cedex, Guadeloupe, France (e-mail: lisa.vidil@univ-ag.rf) re-wetting known as hornification. During the process, the fiber structure changes. The outer wall of cells collapses, followed by hardening. As a result of this effect, the water absorption capacity and swelling of fibers are decreased [7], [8].

The reduced capacity of water absorption of cellulosic fibers allows obtaining beneficial effects when they are incorporated into the cement matrix: the fibers exhibit a greater dimensional stability, enabling a better adhesion between the fibers and the matrix. Furthermore, the formation of calcium hydroxide incrustations on the lumen and surface of cellulosic fibers decrease, causing a reduction in the deterioration of the cellulosic material in the cement matrix [9]. In the present study, the effects of 4 cycles of drying and rewetting on the morphology and physical stability of bleached and unbleached cellulosic pulp of eucalyptus were evaluated to define its potential use as reinforcement of cement based inorganic matrices.

\section{MATERIALS AND METHODS}

\section{A. Materials}

Bleached (Eucalyptus Bleached Kraft Pulp-ECF) and unbleached fibers of eucalyptus (taken at the beginning of the bleaching process) were supplied by the company Suzano Papel e Celulose (Suzano/SP, Brasil). The bleached pulp of eucalyptus is presented in a dry sheet form. The unbleached eucalyptus pulp is disintegrated with $65 \%$ relative humidity.

\section{B. Pulp Treatment}

The process of horrification of eucalyptus pulps consisted of 4 cycles of drying and rewetting, as follows: (1) drying the pulp in an oven with air circulation at $60^{\circ} \mathrm{C}$ for $7 \mathrm{~h}$; (2) rewetting by immersion in water at room temperature for $15 \mathrm{~h}$; (3) disintegration of wet cellulose pulp in a disintegrator (30.000 rpm) [10]; (4) filtering the pulp suspension through a Buchner funnel equipped with a wire screen (150 mesh). At the end of the process (after 4 cycles), the fibers were stored in sealed plastic bags until their subsequent use (methodologies taken and modified from [9]).

\section{Morphology}

Samples of treated and untreatedpulpwere fixed on metallic support ("stub") using carbon double face tape. Then, the fibers were placed in a low vacuum scanning electron microscope (SEM), brand Hitachi - model TM-3000, coupled with $\mathrm{x}$-rays microanalysis system by energy dispersive spectroscopy. Working with low vacuum allows seeing the samples without metallic covering. A voltage of $15 \mathrm{kV}$ was used. The images were formed by acquisition of backscattered electrons at different magnifications. 


\section{X-Ray Diffractometry}

To measure the crystalline index of the cellulose pulp before and after treatment, the method of X-ray diffractometry (XRD) was used. The crystallinity index of cellulose pulps was determined using the empirical procedure proposed in [11]. This method consists incalculating the index of crystallinity for cellulose (Cr.I.), according to the following equation (1):

$$
\operatorname{Cr} . I: \frac{l_{002}-l_{a m}}{l_{002}} \times 100
$$

where $l_{002}$ correspondsto the maximum intensity of diffraction (crystalline) of plane (002) at $2 \theta: 22.6^{\circ}$ and I am
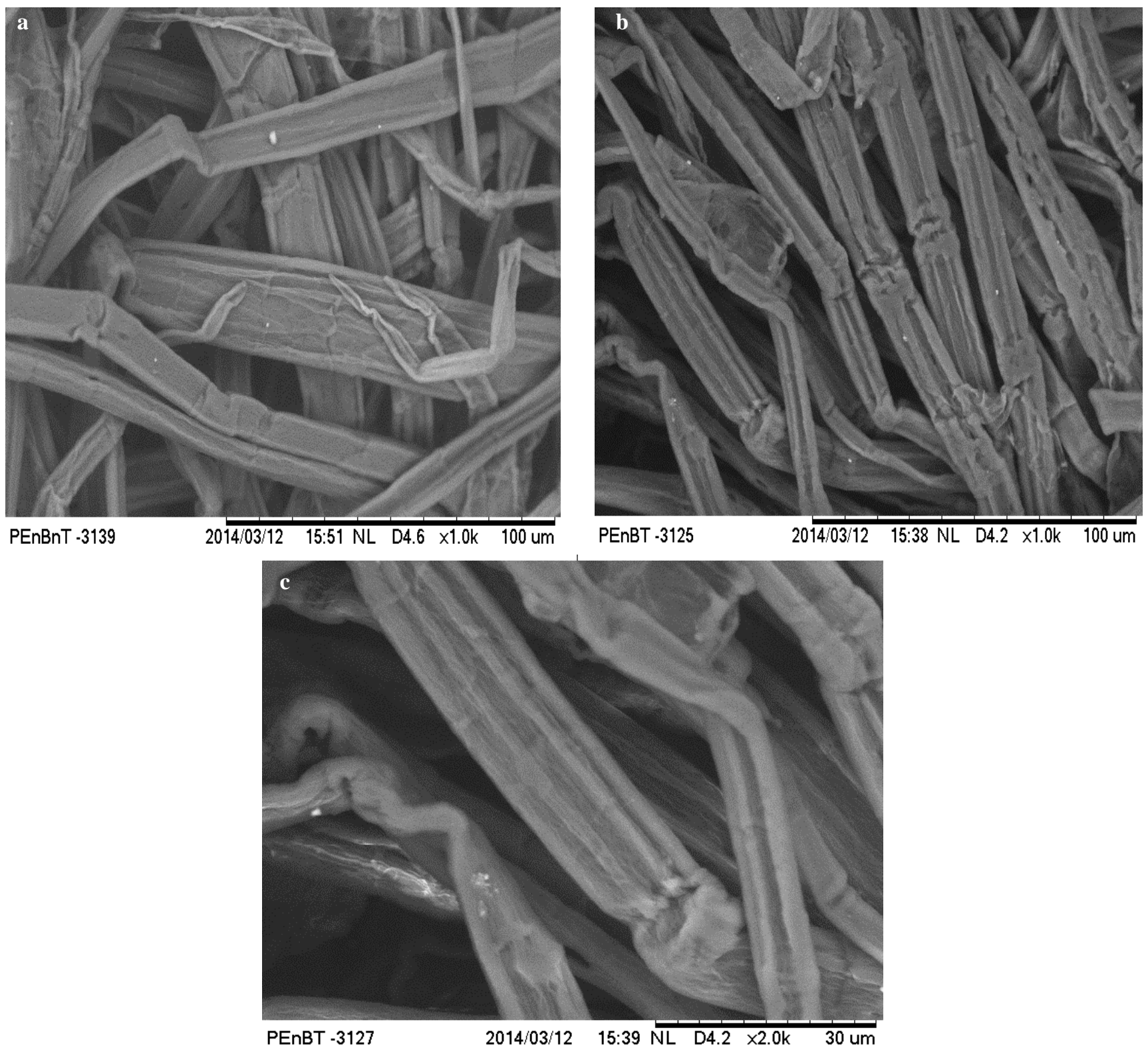

Fig. 1. Images from scanning electron micrographs of (a) eucalypt unbleached pulp without treatment (b) eucalypt unbleached pulp hornificated (magnification range $\times 1.0 \mathrm{k})(\mathrm{c})$ eucalypt unbleached pulp hornificated (magnification range $\times 2.0 \mathrm{k})$.

This effect may be beneficial to improve the performance and behavior of the pulps as reinforcement of cementitious matrices. Indeed, it makes the fibers lose their water absorption capacity and swelling and may enable them to get a greater dimensional stability and to be less damaged. refers to the intensity of the background scatter (amorphous) measured at $2 \theta: 16.6^{\circ}$. The values $l_{002}$ and lam were obtained directly from diffractograms of studied pulp.

\section{RESULTS AND DISCUSSION}

\section{A. Morphological Characterization of the Pulps}

The hornification refers to the irreversible loss of water retention capacity of the fibers due to the formation of hydrogen bonds in cellulose, without changing its mechanical properties [12]-[14]. The treatment produces changes in the surface of the pulp, mainly observed in the collapse and hardening of the outer wall of the cells. 
However, a significant distance between the lateral sides of the pulps indicates there is not a total collapse of the lumen. When this occurs, the front wall and the posterior wall make contact in the center of the pulp, causing a higher decrease in the distance between the lateral sides of the fiber and a greater curvature. This morphology tendency can be observed for the treated specimens of eucalyptus (b) due to the cycles of drying and rewetting.

Furthermore, the untreated eucalyptus pulps present a smoother outer surface compared to the treated ones (c). Besides, the higher roughness of the hornificated fiber surface is expected after treatment due to the contraction of the cell walls.

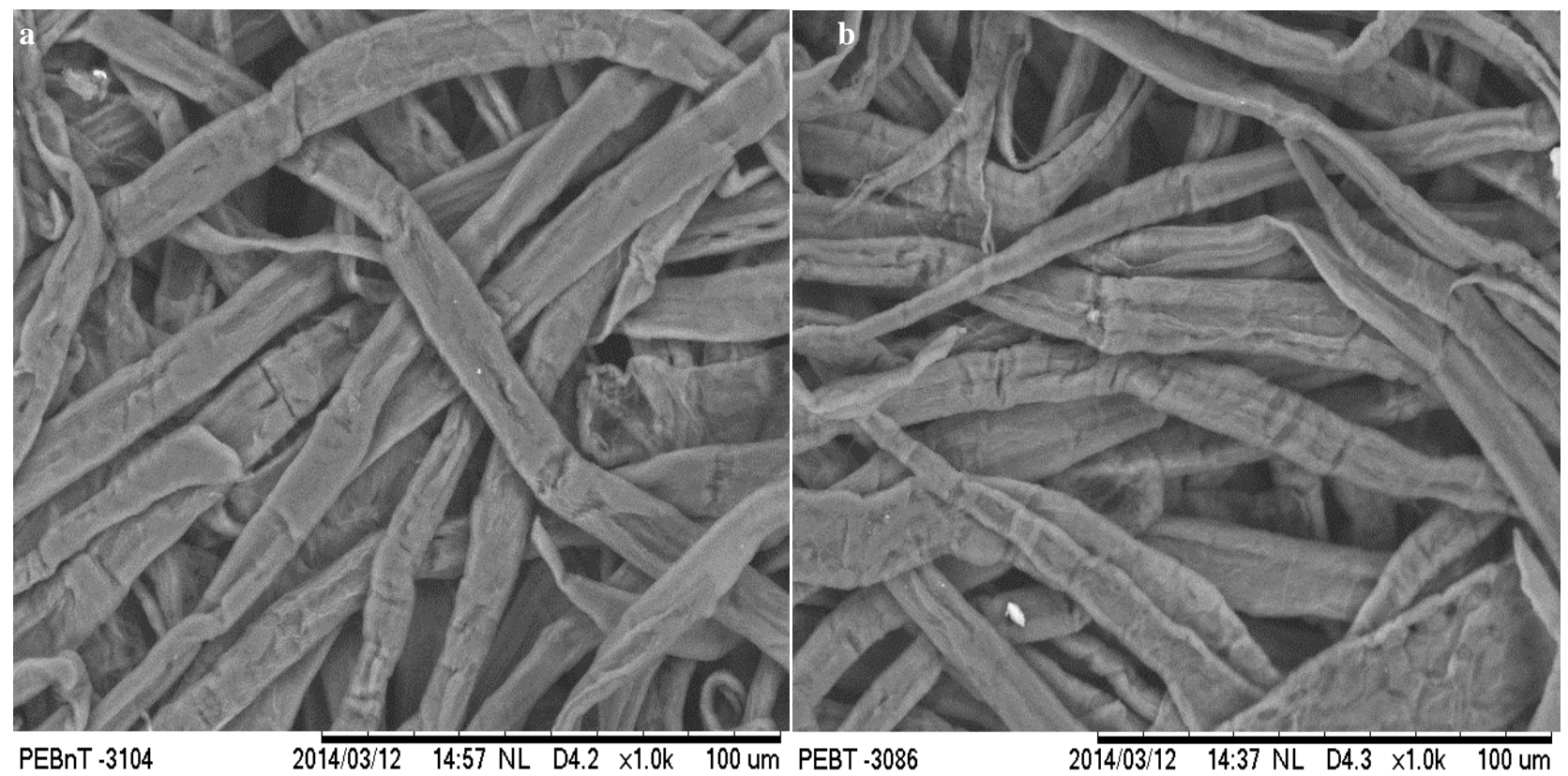

PEBnT -3104

$2014 / 03 / 12 \quad 14: 37$ NL $\quad$ D4.3 $\times 1.0 \mathrm{k} \quad 100 \mathrm{um}$

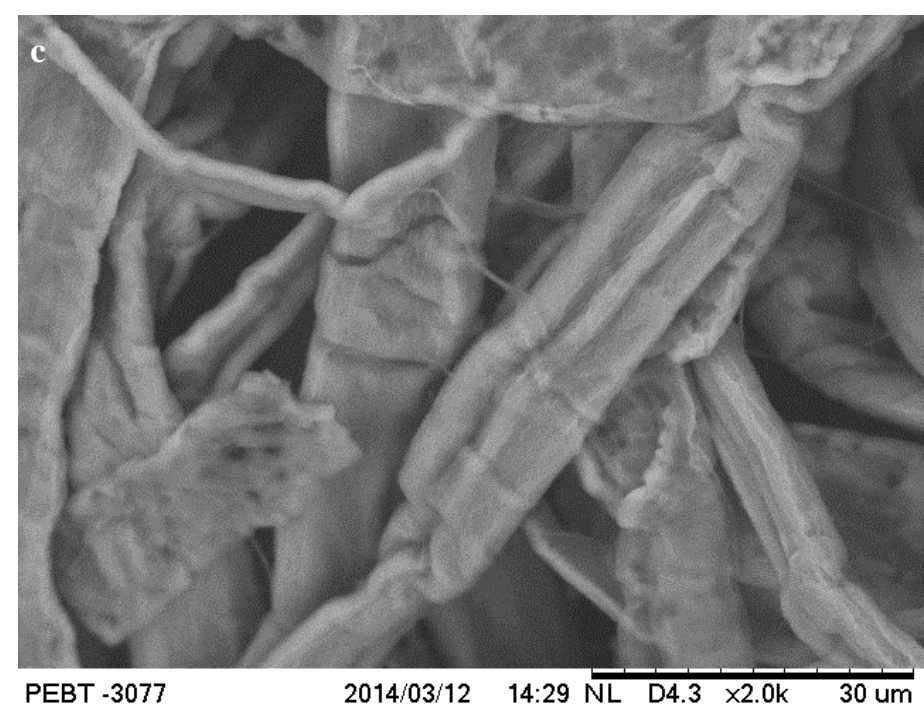

Fig. 2. Images from scanning electron micrographs of (a) eucalypt bleached pulp without treatment (b) eucalypt bleached pulp hornificated. (magnification range $\times 1.0 \mathrm{k})(\mathrm{c})$ eucalypt bleached pulp hornificated (magnification range $\times 2.0 \mathrm{k}$ ).

TABLE I: ALTERATION OF THE CRYSTALLINITY INDEX OF CELLULOSE BY HORNIFICATION

\begin{tabular}{ccc}
\hline \hline Cellulose Pulp & 0 cycles & 4 cycles \\
\hline Eucalypt Unbleached & 65.36 & 65.18 \\
Eucalypt Bleached & 65.70 & 66.76 \\
\hline \hline
\end{tabular}

In Fig. 2, treated (a) and untreated (b-c)bleached eucalyptus pulps show the same morphological change (fiber collapse) but with less intensity than the one for the unbleached pulps. This behavior can be explained by the fact that bleached eucalyptus fibers are obtained in the form of sheets. In this way, bleached pulpshave beenalready subjected to a drying process. However, untreated bleached eucalyptus fibers (a)exhibit a smoother surface with some soft wrinkles.

Ref. [14] showed similar results comparing initially undried pulps of conifers with dried cotton pulps in sheet format (1 drying cycle).

\section{B. Physical Characterization of the Pulps}

Physical characterization of cellulosic pulps was made by X-ray diffractometry analysis on bleached and unbleached eucalyptus fibers, untreated and treated by hornification process. The objective of this characterization was to check the alterations in the crystallinity of cellulosic material. Indeed, the crystalline cellulose is responsible for the mechanical properties of the fibers, such asthe modulus of elasticity and the modulus of rupture. 


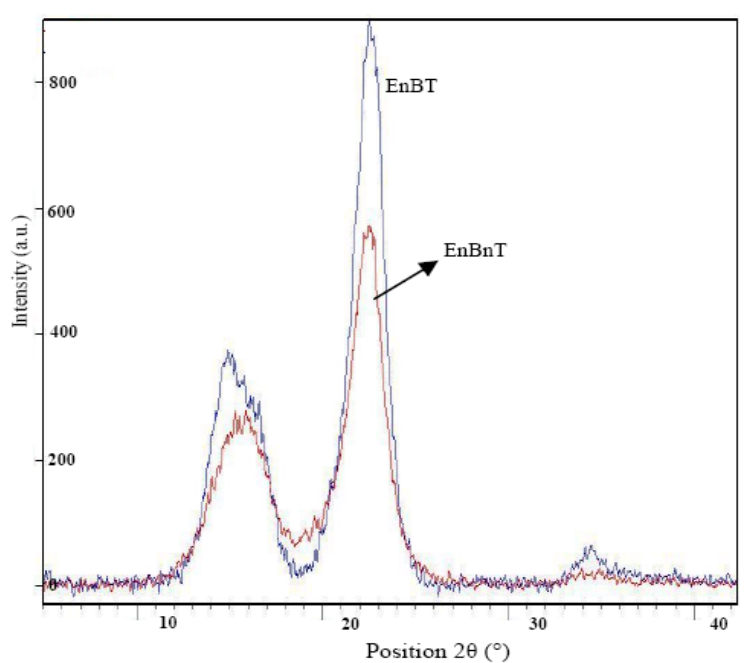

Fig. 3. XRD behavior of eucalypt unbleached treated and untreated.

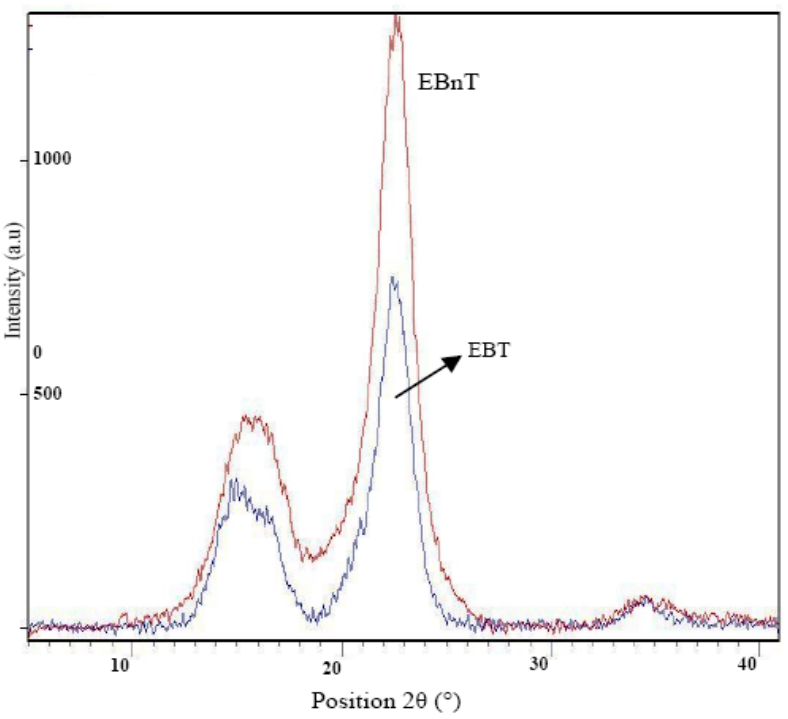

Fig. 4. XRD behavior of eucalypt bleached treated and untreated.

The Table I show the crystalline index of bleached and unbleached eucalyptus pulpsbefore and after the hornification treatment. The Fig. 3 and Fig. 4 present theXRD patterns of these pulps.

In Table I, an increase in the crystalline index of the treated bleached eucalyptus pulp is noticed. For unbleached eucalyptus pulp, there is an inverse trend. Similar results were presented by [14], where bleached coniferous fibers showed a crystallinity index $10 \%$ higher than the one of unbleached conifer fibers. However, the variations of crystalline index indicated in this study are small. Thus, we can consider the crystalline indexes are not different significatively, indicating that, the process of hornification hasn't caused important modification or degradation of crystalline cellulose of the treated fibers.

In Fig. 3 and Fig. 4, the peaks corresponding to the maximum intensity of diffraction of plane (002) at $2 \theta: 22,6^{\circ}$ and the peaks referring to the intensity of background scatter at 20: $16.6^{\circ}$ can be seen.

\section{CONCLUSION}

Based on the results obtained during the development of this research, it is possible to define some specific effects the hornification treatment had on the studied pulps:

- It was proved that by submitting the pulps to 4 cycles of drying and rewetting,changes in surface structure occuredby collapsing the cell wall.

- The effect of the treatment was more significant in unbleached eucalyptus pulp, which had not been subjected to a drying process before being treated.

- The XRD results indicated that the hornification treatment did not cause deterioration of crystalline cellulose of treated bleached and unbleached fibers

\section{REFERENCES}

[1] B. J. Mohr, H. Nanko, and K. E. Kurtis, "Durability of kraft pulp fiber-cement composites to wet/dry cycling," Cem Concr Compos, vol. 27, pp. 435-448, 2005.

[2] C. L. Roma, L. S. Martello, and H. J. Savastano, "Evaluation of mechanical, physical and thermal performance of cement-based tiles reinforced with vegetable fibers," Construct Build Mater, vol. 22, pp. 668-674, 2008.

[3] R. D. Tolêdo Filho, K. Scrivener, G. L. England, and K. Ghavami, "Durability of alkali-sensitive sisal and coconut fibres in cement mortar composites," Cement \& Concrete Composites, vol. 22, pp. 127-143, 2000.

[4] H. J. Savastano, P. G. Warden, and R. S. P. Coutts, "Brazilian waste fibre as reinforcement for cement based composites," Cement \& Concrete Composites, vol. 22, pp. 379-384, 2000.

[5] K. Bilba and M. A. Arsene, "Silane treatment of bagasse fiber for reinforcement of cementitious composites," Composites, vol. 39, pp. 1488-1495, 2008

[6] J. L. Pehanich, P. R. Blankenhorn, and M. R. Silsbee, "Wood fiber surface treatment level effects on selected mechanical properties of wood fiber-cement composites," Cem Concr Res, vol. 34, pp. 59-65, 2004.

[7] J. Turrado, A. R. Saucedo, J. Ramos, and M L. Reynoso, "Comportamiento de la fibra de celulosa reciclada en el proceso de hidratación," Información Tecnológica, vol. 19, no. 5, pp. 129-136, 2008.

[8] T. Köhnkea, K. Lundb, H. Brelidb, and G. Westman, "Kraft pulp hornification: a closer look at the preventive effect gained by glucuronoxylan adsorption," Carbohydrate Polymers, vol. 81, pp. 226-233, 2010.

[9] J. Claramunt, M. Ardanuy, J. A. G. Hortal, and R. D. Tolêdo, "The hornification of vegetable fibers to improve the durability of cement mortar composites," Cement \& Concrete Composites, vol. 33, pp. 586-595, 2011.

[10] International Organization for Standarization (ISO) 5263-1. Pulps Laboratory Wet Disintegration - part 1: Disintegration of chemical pulps, 2004.

[11] L. Segal, J. J. Creely, A. E. Martin, and C. Conrad, "An empirical method for estimating the degree of crystallinity of native cellulose using the x-ray diffractometer," Text Res, vol. 29, pp. 786-794, 1959.

[12] G. Jayme, "Milkro-quellungsmessungen a Zellstoffenn," Papier-Fabr/Wochbl Papierfabr, vol. 6, pp. 187-194, 1944.

[13] A. D. Bawden and R. P. Kibblewhite, "Effects of multiple drying treatments on kraft fibre walls," J Pulp Pap Sci, vol. 23, no. 7, pp. 340-346, 1997.

[14] J. Claramunt, M. Ardanuy, and J. A. G. Hortal, "Effect of drying and rewetting cycles on the structure and physicochemical characteristics of softwood fibres for reinforcement of cementitious composites," Carbohydr Polym, vol. 79, pp. 200-205, 2010.

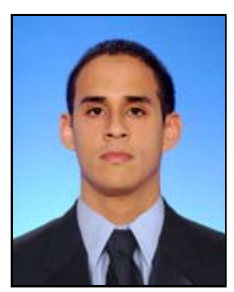

Julian Eduardo Mejia Ballesteros was born in the state Valle Del Cauca, Colombia on July 21, 1985. He was graduated in environmental engineering from the National University of Colombia in the city of Palmira, Valle del Cauca, since 2003 until 2008. In 2012, he joined the master's program in animal science at the Faculty of Animal Science and Food Engineering, University of Sao Paulo, Campus Pirassununga. He has experience in the area of rural construction and engineering of materials, acting on the following topics: reinforced cement based inorganic matrices by vegetables fibers, rural construction and sustainability. 